МАЙЕР Евгения Александровна - магистрант образовательной программы «Политическое управление» Башкирской академии государственной службы и управления при Главе Республики Башкортостан (450002, Россия, Республика Башкортостан, г. Уфа, ул. Тукаева, 46; е.а.тауег@ ya.ru)

\title{
ПРОТОКОЛ И ГЕНДЕР
}

\begin{abstract}
Аннотация. Предметом исследования данной статьи являются нормы дипломатического протокола, регулирующие отношения между странами, в лицах, представляющих их на переговорных процессах. Эти лица имеют свою субъектность: должностную иерархию, гендер, социальный статус и т.д. До сих пор существует тенденция разделять стили ведения переговоров на «мужской» и «женский», и некоторые ультраконсервативные мужчины отказываются вести деловые переговоры с женщинами, относятся к ним скептически и показывают свое необоснованное превосходство. Такое недипломатичное отношение в переговорных процессах в отношении женщин, их дискриминация в политической и бизнес-среде в мусульманских странах, а также противоречия между законными правами женщин и религиозными ограничениями тех же прав недопустимы в современном деловом мире. Обеспечивать конструктивный диалог людей разной субъектности призвано искусство дипломатии, а фиксирующим документом, регулирующим нормы, правила поведения и тон переговоров, является дипломатический протокол.
\end{abstract}

Ключевые слова: протокол, гендер, переговоры, sofagate, фрейм, стереотипы, принципы, религия, политика, иерархия

Санкция, связанная с нарушением юридического обязательства, порой не менее реальна, чем та, что возлагается за неуважение чисто морального или политического обязательства.

П. Вейль

\begin{abstract}
$\mathrm{C}$ уществует точка зрения, что дипломатический протокол является показателем хороших манер в отношениях между странами, а дипломатический этикет, соответственно, - выражением и характеристикой взаимоотношений между политиками и дипломатами этих стран. Основой правил международного дипломатического протокола является принцип вежливости, включающий в себя набор общепризнанных в международной практике правил этикета, уважения и почтительности. Эти правила тщательно соблюдаются в межгосударственных отношениях. Нарушение данных правил воспринимается как нанесение ущерба авторитету и престижу государства. Все участники переговоров должны четко соблюдать протокол и его предписания независимо от должности, статуса или гендера. В западном мире роль женщиныдипломата, женщины-политика или женщины-бизнесмена не вызывает противоречивых чувств и мизогинии. Актуальность темы данной статьи поддерживается тенденцией к равенству и необходимостью жесткого отстаивания женщинами своих прав на самоактуализацию при патриархальных издержках современного мира. Медленная эскалация участия женщин в мировых процессах бизнеса и политики сохраняет свою динамику при сохранившихся консервативных представлениях о гендерных правах и обязанностях в социуме. На международной арене число женщин, участвующих в переговорах на высшем уровне, увеличивается из года в год, подтверждая тем самым успешность разрешения конфликтов и сделок, решения по которым принимают женщины.

Предметом исследования данной статьи являются стереотипы поведения, шаблоны, основанные на гендерных фреймах, по которым мы выстраиваем
\end{abstract}


общественные отношения. Это стандартные базовые паттерны, исходящие из природных инстинктов для выживания человеческого вида, сохранения энергии и вылившиеся в первичную культуру координации общества. Развитие человека и осознание им себя как индивидуума, развитие технологического, индустриального и цифрового мира разрешает нам быть свободными от модели природного поведения, основной целью которого является выживание.

Задача данной статьи - попытаться ответить на вопросы, как в протоколе учесть все интересы субъектов переговоров, когда что-то в одной стороне считается ущемлением прав и дискриминацией, а в другой - традиционным отношением? Как быть с тем, что в нашем мире на гендерный контекст выстраивания взаимоотношений, накладываются и другие социальные роли при установившихся вековых разделениях полномочий между мужчиной и женщиной? Как быть с тем, что воспитывающееся на этих культурных идентичностях поколение нынешних дипломатов, политиков и бизнесменов с трудом принимает изменившееся положение женщин, вторгнувшихся в так называемый мир мужских игр. Сформировавшиеся гендерные модели поведения и наложенные на них различные социальные роли не позволяют субъекту (мужчине) во время деловых переговоров точно выяснить, как именно себя вести с субъектом (женщиной), особенно если переговоры проходят между странами, имеющими разнополюсные ценности. Для мирного ведения диалога нужны правила, регулирующие поведение в рамках дозволенных границ, а также личное отношение, не скорректированное природными гендерными рамками. Для этого необходим дипломатический протокол, усмиряющий и сдерживающий природную внутривидовую агрессию и гендерные фреймы специальными ритуалами.

\section{Sofagate}

За объект исследования данной проблемы был взят инцидент, происшедший 6 апреля 2021 г. в Анкаре во время протокольной съемки на переговорах представителей ЕС с президентом Турции Реджепом Тайипом Эрдоганом, когда главе Еврокомиссии (ЕК) Урсуле фон дер Ляйен не досталось кресло рядом с президентом Турции. На встрече также присутствовал председатель Евросовета Шарль Мишель, который расположился рядом с президентом Турции на одном из двух выделенных кресел, а главе Еврокомиссии пришлось присесть на диван, в стороне, напротив турецкого министра иностранных дел Мевлюта Чавушоглу, не равного ей по рангу в протокольной иерархии.

Различные люди могут представлять интересы государств, сообществ или общественных групп. Сейчас представительство официальных делегаций в структурах власти и сфере бизнеса во многом представлено мужчинами, особенно в странах с исламским вероисповеданием, что показывает исследование Global Gender Gap Report 2020.

Характеристикой взаимоотношений между политиками и дипломатами стран - участниц переговоров могут служить не только официальная встреча и сотрудничество, но также уровень приема послов других стран, следование их традициям, культуре, уважительное отношение, которое выказывается в жестах, мимике, поведении, манере речи, позе [Мокшанцев 2002]. Необходимо держаться границ дозволенного, чтобы действия одной из сторон не были истолкованы неправильно. Случайные эпизоды могут нанести ущерб репутации или восприняты как вызов не только личный, но и всей стране в целом, что может повлечь за собой серьезные последствия и усложнить отношения между странами.

«Что касается восприятия (Евро)комиссии за рубежом, разумеется, про- 
токольный ранг ее председателя точно такой же, как и у председателя Европейского совета. Кстати, председатель (ЕК) является полноправным членом Европейского совета, и обычно, когда она направляется в зарубежное государство, к ней относятся точно таким же образом, как это было бы сделано в отношении председателя Европейского совета», - объяснил официальный представитель ЕК Эрико Мамер ${ }^{1}$.

Согласно имеющейся информации ${ }^{2}$, основная вина за инцидент лежит на протокольной службе Шарля Мишеля, которая занималась подготовкой встречи вместе с администрацией турецкого президента. Во-первых, сотрудники Мишеля не должны были соглашаться с расположением кресел, из-за которого председатель Европейской комиссии была низведена до ранга министра иностранных дел Турции, сидевшего на другом диване напротив нее.

Данным расположением кресел при приеме официальной делегации ЕС Турция показала консервативность своих взглядов в отношении женщин, обесценила принципы, построенные европейским миром, стремящимся к гендерному равенству, и утвердилась в своем решении о выходе из Стамбульской конвенции Совета Европы «О предотвращении и борьбе с насилием в отношении женщин и домашним насилием», что, по официальной версии, было обусловлено нечеткой интерпретацией описания полов 3 .

Намеренное нарушение дипломатического этикета всегда расценивается как рассчитанная демонстрация недоверия к дипломату и неизбежно отражается на отношениях между субъектами переговоров - представителями стран. Любое нарушение этих правил создает трудности для стороны, допустившей нарушение, т.к. она должна будет принести извинения и найти способ исправить ошибку.

С одной стороны, Турция стремится быть в повестке европейского мира, принимая законы о домашнем насилии, с другой - хочет сохранить незыблемые правила, установленные системой шариата: подчиненное положение женщины на основании «естественного превосходства» мужчины. Религия в любых странах является социальным институтом и поэтому выполняет различные общественные задачи, среди которых - формирование представления о мире и поддержание культурных норм, контроль за их выполнением, в т.ч. и тех, которые формируют понятие гендерных ролей и устойчивых стереотипов поведения.

Можно привести пример надлежащей практики. Споры по поводу результатов президентских выборов в Кении в декабре 2007 г. привели к возникновению кризиса, в ходе которого погибли более 1000 чел., а сотни тысяч оказались в положении перемещенных лиц. При посредничестве бывшего Генерального секретаря ООН Кофи Аннана участники переговоров попытались найти путь для выхода из кризиса, примирения общин и для предупреждения конфликта в будущем. Комиссия ЕС поставила специальное условие соответствующим делегациям, по которому в состав групп переговорщиков должны были входить женщины. В результате в составе обеих групп переговорщиков (по четыре человека в каждой) оказалось по одной женщине. Женщины-переговорщики и женские организации Кении сыграли существенную роль, предложив решение долгосрочных проблем: конституционную, правовую и институциональную

\footnotetext{
1 Главе Еврокомиссии не выдали стул на переговорах с Эрдоганом в Анкаре. Доступ: https://www.interfax.ru/world/759995 (проверено 09.01.2022).

2 В корне кризиса вокруг протокола лежат внутренние разногласия в ЕС. Доступ: http:// surl.li/zevw (проверено 09.01.2022).

3 Турция объяснила выход из конвенции по защите женщин подменой ее сути. Доступ: https://www.rbc.ru/politics/22/03/2021/6057faca9a794734d480ec8d (проверено 09.01.2022).
} 
реформы; искоренение причин насилия, вспыхнувшего после выборов; повышение прозрачности и подотчетности действий властей, а также решение проблемы безнаказанности за преступления.

Однако даже несмотря на то, что права женщин могут законодательно охраняться государством, люди могут не воспринимать это всерьез. Например, несмотря на наличие в Кыргызстане институционализированного государственного аппарата, в управлении государством большую роль, помимо официальных институтов, играют старейшины и общины, которые оказывают большое влияние на государственный аппарат. Они охраняют исторические и религиозные традиции и позволяют то, что не позволяется законодательством. Из-за этого у девушек в Киргизии даже при наличии законов, защищающих их права, нет ощущения безопасности, т.к. старейшины и общины обладают большим авторитетом и большей поддержкой со стороны общества.

\section{Выводы}

Установленные гендерные различия или неравенство подкрепляются выгодами, которые гендерные границы дают людям при понимании себя и других. Будучи институционализированными культурными правилами, гендерные представления о различиях и неравенстве имеют преимущество в регламентации, которое люди применяют с дозволением явных нарушений ${ }^{1}$.

Не стоит исключать из сферы внимания влияние на поведение при переговорах факта природной агрессии, выраженной в самоутверждении за счет унижения другой стороны. Высказанная доминанта, сохранившаяся до нашего времени в поведении мужчин по отношению к женщинам, ставит под сомнение результат деловых переговоров. В протоколе важно учитывать равноправное положение по иерархии должностей. Переговоры должны проходить на одном уровне, и гендер человека на занимаемой должности не должен регулировать, влиять и менять положение условий переговоров и их решений.

В России ситуация в отношении дипломатии и переговоров с женщинами стоит так же остро. Причины этого были выведены в результате исследований, проведенных Центром политической конъюнктуры (ЦПК) («Популяризация традиционных ценностей и запрос на “сильную руку” меняют представления россиян о женщине в политике») в 2020 г. Базовым фактором недопуска женщин в дипломатию, бизнес и политику является то, что российское общество остается консервативным. Большую роль здесь играет активная политика государства по продвижению традиционных ценностей, которые доминируют в «старых» медиа и в официальном языке власти: в них образ женщины зафиксирован как мать, бабушка и переплетен с домом и семьей. Также в общественном сознании сохраняется высокий запрос на «сильную руку», которая прежде всего ассоциируется с маскулинностью, мужчиной.

Этот анализ предполагает, что изменения в гендерной системе общества будут повторяться, и они не всегда будут проходить гладко. Движущей силой перемен становятся политические, экономические и технологические факторы, которые изменяют повседневную диспозицию между мужчинами и женщинами таким образом, что подрывают традиционные взгляды на различия в статусе между ними ${ }^{2}$.

\footnotetext{
${ }^{1}$ Как гендер формирует социальные отношения. Доступ: https://doxajournal.ru/ translations/gender_frame (проверено 09.01.2022).

2 Там же.
} 
Список литературы

Мокшанцев Р.И. 2002. Психология переговоров: учебное пособие. М.: ИНФРА-М; Новосибирск: Сибирское соглашение. 352 с.

MAIER Evgeniya Aleksandrovna, Master's student of the educational program «Political Management», Bashkir Academy of Public Administration and Management under the Head of the Republic of Bashkortostan (46 Tukaeva St, Ufa, Republic of Bashkortostan, Russia, 450002; e.a.mayer@ya.ru)

\section{PROTOCOL AND GENDER}

Abstract. The article aims at studying the norms of the diplomatic protocol regulating relations among countries through persons representing them in negotiation processes. However, the representatives are prone to their own subjectivity because of their job hierarchy, gender, social status, etc. There is still a tendency to divide negotiating styles into «male» and "female», while some ultra-conservative men refuse to conduct negotiations with women, being skeptical about them and deliberately showing their unreasonable superiority. Such a non-diplomatic attitude towards women in negotiation processes, their discrimination in the political and business environment in Muslim countries, as well as contradictions between the legal rights of women and religious restrictions on the same rights are no longer acceptable in the modern business world. The art of diplomacy is aimed to provide a constructive dialogue between people of different subjective views, and the diplomatic protocol is to be the document that keeps records and regulates the norms, rules of conduct, and the tone of negotiations. Keywords: protocol, gender, negotiation, sofagate, frame, stereotypes, principles, religion, politics, hierarchy 